\title{
Woman abuse and pregnancy outcome among women in Khoram Abad, Islamic Republic of Iran
}

N. Khodakarami, ${ }^{1}$ H. Naji, ${ }^{2}$ M.G. Dashti ${ }^{3}$ and M. Yazdjerdi ${ }^{4}$

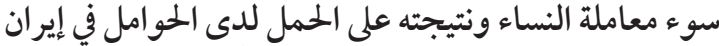

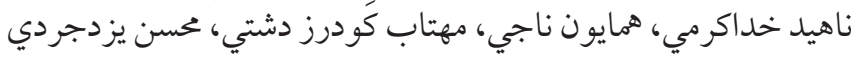

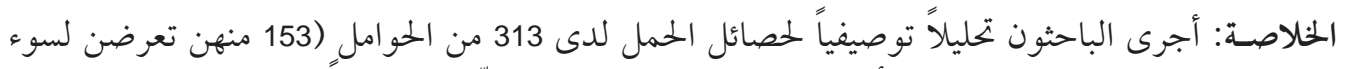

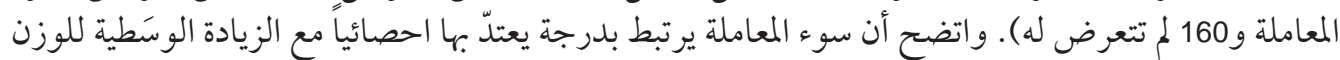

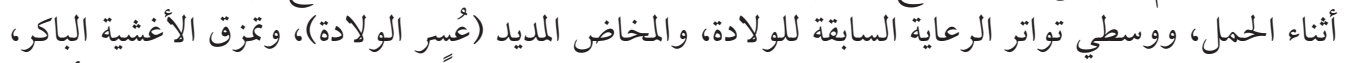

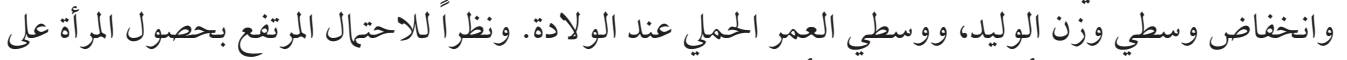

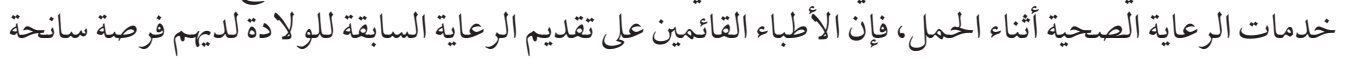

$$
\begin{aligned}
& \text { لتحري سوء معاملة الزوج لزوجته. }
\end{aligned}
$$

ABSTRACT We carried out a descriptive analysis on the pregnancy outcome in 313 pregnant women (153 abused, 160 non-abused). Abuse was statistically significantly correlated with mean weight gain during pregnancy, mean frequency of the prenatal care, prolonged labour (dystocia), premature rupture of membrane, low mean birth weight and mean gestational age at birth. Given the high likelihood that a woman will access health care services during her pregnancy, physicians providing prenatal care are in a strategic position to screen for partner abuse.

\begin{abstract}
Violence contre les femmes et issue de la grossesse chez des femmes de Khoram Abad (République islamique d'Iran)

RÉSUMÉ Nous avons réalisé une analyse descriptive de l'issue de la grossesse chez 313 femmes enceintes (153 victimes de violences et 160 qui ne l'étaient pas). II y avait une corrélation statistique significative entre les violences et une prise de poids moyenne pendant la grossesse, une fréquence de soins prénatals moyenne, un accouchement laborieux (dystocie), une rupture prématurée de la membrane, un poids moyen à la naissance faible et un âge gestationnel moyen à la naissance. Dans la mesure où il existe une forte probabilité qu'une femme se rende dans des services de soins de santé pendant sa grossesse, les médecins dispensant les soins prénatals sont bien placés pour dépister les violences conjugales.
\end{abstract}

'Shahid Beheshti Medical University, Reproductive Health Research Centre and Nurisng Midwifery School, Tehran, Islamic Republic of Iran (Correspondence to N. Khodakarami: khodakarami@sbmu.ac.ir). ${ }^{2}$ Nursing Midwifery School of Isfahan Medical University, Isfahan, Islamic Republic of Iran.

${ }^{3}$ Asali Hospital, Khoram Abad, Islamic Republic of Iran.

${ }^{4}$ Shahid Beheshti Medical University, Nursing Midwifery School, Tehran, Islamic Republic of Iran.

Received: 25/09/06; accepted: 13/12/06 


\section{Introduction}

Violence during pregnancy is one of the most tragic and little known aspects of gender-based violence. It has serious effects on the mental and physical health of the women involved. Research indicates the prevalence of intimate partner violence during pregnancy to range from $0.9 \%$ to $20.1 \%$ [ $1-3]$. The rate of abuse by partners among Iranian women is $17.0 \%$ $29.3 \%$, of which the most common forms are verbal and psychological abuse [4,5].

Some authors postulate that pregnancy itself is a risk facor for increased abuse: while some victims of domestic violence experience a decrease in physical abuse during pregnancy, many other women report that the abuse started or increased during their pregnancies [6]. Research on the relationship between violence and adverse pregnancy outcome is sparse and the results are conflicting; however, some studies have reported that women who are abused during pregnancy are at high risk for complications [7,8]. According to the Centers for Disease Control and Prevention, abuse during pregnancy may be more common than gestational diabetes, neural tube defect, and pre-eclampsia [9].

Intimate partner violence during pregnancy has been associated with an increased incidence of abruptio placentae, spontaneous abortion, premature labour and birth, low birth weight, and perinatal death [9-12]. Other negative effects include increased behavioural, somatic and stress-related conditions, such as tobacco, alcohol and drug use; increased use of medications; increased suicide rate, etc. $[1,13]$. Complications of pregnancy, including low weight gain, anaemia, infections and first/second trimester bleeding, are significantly higher for abused women [13,14]. Additionally, when compared to women abused before pregnancy, those abused during pregnancy had more risk factors for homicide [15]. Clearly, abuse during pregnancy is a major threat to the health and survival of pregnant women. The purpose of this study was to identify the relation between women abuse and pregnancy outcome.

\section{Methods}

This was a cross-sectional study conducted between 10 September 2001 and 25 May 2002.

To be eligible for the study, women had to be of Iranian nationality, speak Farsi and be at least 20 weeks pregnant. Women were approached during presentation at the labour and delivery unit of the Khoramabad Hospitals (Asali and Tamin Ejtemaei). Of the 512 women approached, 419 were eligible for the study; 106 refused to participate, leaving 313 women in the study group.

The study was approved by the institutional review boards at each hospital. Women who were eligible for the study were asked by the research assistant (a qualified midwife) if they would be willing to talk to the research officer/midwife about a study. If the woman agreed, they met in private so that they could fully discuss the study and written informed consent was obtained from the participants. The consent process ensured confidentiality by using study numbers rather than names, keeping all records in a locked filing cabinet; ensuring the information was not made part of the woman's medical record, and through a Certificate of Confidentiality obtained from Isfahan Medical University Ethics Committee. Women were also informed that their medical records would be assessed by the researcher but that the information would only be identified by the study number.

Each woman who agreed was interviewed face-to-face using a validated questionnaire to assess partner abuse. Each was asked if her partner had physically hurt her, insulted her or talked down to her; threatened her with harm; sexually abused her; or

المجلة الصحية لشرق المتوسط، منظمة الصحة العالمية، المجلد الخامس عشر، العدد ب، 9 +. 
screamed or cursed at her during the current pregnancy. Women answering yes to any question were classified as abused; those answering no to all questions comprised the non-abused group.

The first assessment instrument took approximately 30 minutes to complete and included sociodemographic characteristics and the prenatal care profile. A second assessment was completed in the post-partum ward within 24 hours of the birth to collect information on pregnancy outcome and duration of labour, etc.

Among the women classified as abused, partner abuse was measured via an interview using a questionnaire based on a series of tools: Index of Spousal Abuse [16]. Abuse Assessment Screen [17], Woman Abuse Screening Tool [18], Partner Violence Screen [19], and Severity of Violence Against Women Scale [17,20]. Women were also asked whether the husband had behaviour problems, assessed through 5 questions regarding their conduct and relationships (withdrawn, antisocial, having problems at work, with family members or in the community).

All instruments were culturally modified and questions were in Farsi and were administered by the investigators (midwives) in a private room without the male partner present. After these questionnaires were completed, participants completed a confidential self-report on tobacco, alcohol and drug use by herself and her husband. All women who were positive for intimate partner abuse on the Abuse Assessment Screen were administered the Danger Assessment Screen [21].

All analyses evaluating the association between abuse during pregnancy and pregnancy outcome were adjusted for the woman's age at pregnancy, education, family income, parity and characteristics of the husband.
Chi-squared analysis was used for nominal level data and 1-way analysis of variance was used for interval level data (e.g. age or kind of abuse). To explore the relationship of abuse to pregnancy outcome, odds ratios (OR) with $95 \%$ confidence intervals (CI) were calculated, and logistic regression was used to perform outcome analysis. Because confounding factors are known to affect outcomes, the ORs were controlled for maternal age, parity, education, prenatal care, partner substance abuse and family income. Additional multivariate logistic regression analysis was performed to assess the association between intimate partner violence and birth weight and mother's weight gain during pregnancy (details obtained from the antenatal clinic records), controlling for gestational age and family income. All analyses were performed using SPSS, version 6.1a. Statistical significance was set at 0.05 .

\section{Results}

Of the 313 women who participated in the study, 153 had experienced some type of violence during the pregnancy. There were significant associations between the experience of partner violence during pregnancy and several sociodemographic characteristics. Women who experienced abuse during pregnancy had a statistically significantly lower level of education and reported lower levels of family income than those who were not abused (Table 1).

There were statistically significant differences between husbands who were abusers and those who were not with regard to age, education, type of work, substance abuse and having behaviour problems (withdrawn, antisocial, having problems at work, with family members or in the community, etc: this item was assessed through 5 questions regarding their conduct and relationships) (Table 2). 
Table 1 Demographic characteristics of abused and non-abused pregnant women $(n=313)$

\begin{tabular}{lcc}
\hline Variable & Abused $(\boldsymbol{n}=\mathbf{1 5 3})$ & $\begin{array}{c}\text { Non-abused } \\
(\boldsymbol{n}=\mathbf{1 6 0})\end{array}$ \\
\hline Mean (range) age (years) & $21.3(16-39)$ & $26.8(17-40)^{\star \star *}$ \\
Mean (range) education (years) & $8.6(0-16)$ & $10.3(3-16)^{\star * *}$ \\
Mean (range) monthly family & 750000 & $820000(30000-$ \\
$\quad$ income (R) & $(0-1200000)$ & $210000)^{\star * *}$ \\
Married, living with partner (no.) & 152 & 160 \\
\hline aUS\$1 = R 9200 in 2002. & &
\end{tabular}

${ }^{* * * P}<0.001$.

There was a statistically significant difference between the 2 groups of women with regard to frequency of prenatal care, mean maternal weight gain during pregnancy, premature rupture of membranes and dystocia $(P<0.05$ in all cases) (Table 3$)$.

Mean birth weight was significantly lower among infants of the abused mothers $(P=0.02)$ (Table 4).

Logistic regression analysis indicated that abuse during the pregnancy was significantly associated with both low mean birth weight adjusted odds ratio $(\mathrm{AOR})=1.6$; 95\% CI: 1.1-2.3] and mother's weight gain $(\mathrm{AOR}=1.7 ; 95 \% \mathrm{CI}: 1.3-2.6)$ after adjusting for other covariates. The mean birth weight of infants born to women who were abused was significantly lower $(-92 \mathrm{~g})(P$ $=0.02)$ than that of infants of women who were not abused.

\section{Discussion}

In this study we found a significant relationship between lower weight gain in mothers and abuse during pregnancy. Johnson, Hellerstedt and Pirie also reported that women with current abuse had 3.1 times the odds of inadequate prenatal weight gain compared to women who reported no abuse [22]. Macaulay et al. considered that low weight gain in women abused during pregnancy could be a result of decrease in appetite: abused women try to prevent weight gain to escape from their husband's violence [23]. As also reported in another study, we found that women who were subjected to abuse made fewer prenatal care visits [24].

It appears that abuse during pregnancy may also affect birth weight. Our findings showed that neonatal birth weight varied

\begin{tabular}{lccc}
\hline \multicolumn{3}{l}{$\begin{array}{l}\text { Table } 2 \text { Demographic characteristics of partners of participants, } \\
\text { abuser and non-abuser husbands }(\boldsymbol{n}=\mathbf{3 1 3})\end{array}$} & \multicolumn{3}{c}{ Partner of: } & P-value \\
\hline Variable & $\begin{array}{c}\text { Abused } \\
(\boldsymbol{n}=153)\end{array}$ & $\begin{array}{c}\text { Non-abused } \\
(\boldsymbol{n}=\mathbf{1 6 0})\end{array}$ & \\
\hline Mean (range) age (years) & $23.7(14-44)$ & $26.2(16-43)$ & 0.01 \\
Mean (range) education (years) & $7.2(0-16)$ & $10.8(5-16)$ & 0.01 \\
Low income job/no job, no. (\%) & $67(43.8)$ & $42(26.3)$ & 0.001 \\
Drug abuse (tobacco, alcohol, & & & 0.001 \\
$\quad$ narcotics), no. (\%) & $102(66.7)$ & $88(55.0)$ & \\
Behaviour problems, no. (\%) & $38(24.8)$ & $18(11.3)$ & 0.001 \\
\hline
\end{tabular}

المجلة الصحية لشرق المتوسط، منظمة الصحة العالمية، المجلد الخامس عشر، العدد ب، 9 +. 


\begin{tabular}{lccc}
\hline $\begin{array}{l}\text { Table } 3 \text { Selected pregnancy outcome variables in relation to abuse } \\
\text { during pregnancy }\end{array}$ & $\begin{array}{c}\text { Abused } \\
(\boldsymbol{n}=\mathbf{1 5 3}) \\
\text { Variable }\end{array}$ & $\begin{array}{c}\text { Non-abused } \\
(\boldsymbol{n}=\mathbf{1 6 0})\end{array}$ & P-value \\
& $9.5(3.7)$ & $10.9(3.3)$ & 0.01 \\
& $12.4(0.7)$ & $12.2(0.9)$ & NS \\
\hline Mother's weight gain (kg) & & & \\
Haemoglobin (g/dL) & $10.3(2.2)$ & $11.5(1.9)$ & 0.007 \\
Frequency of prenatal care & $2.3(1.6)$ & $2.3(1.8)$ & NS \\
$\quad$ (no. of visits) & No. (\%) & No. (\%) & \\
First prenatal care visit (months) & $48(31.4)$ & $27(16.9)$ & 0.006 \\
& $40(26.1)$ & $23(14.4)$ & 0.01 \\
PROM & & & \\
Dystocia &
\end{tabular}

$S D=$ standard deviation; $N S=$ not significant

$P R O M=$ premature rupture of membranes

according to whether the mother suffered violence during pregnancy. This is in accordance with previous studies indicating that abuse during pregnancy is a significant risk factor for low infant birth weight [25,26]. A 2000 study showed that abuse during pregnancy was significantly associated with an increased risk of preterm, low birth weight and term low birth weight [12].

There was an association between abuse in pregnancy and dystocia during labour. It has been reported that after the first stage, labour may stop in abused women; these women may refuse to push and sometimes they return to the first stage [27]. Lent and Morris noted that labour and delivery can cause problems for women with memories of physical violence, in some instances resulting in complete interruption of labour and delivery [28].

The characteristics of the participants who reported abuse in this study are consistent with other reports [2,29]. Overall, they were significantly more likely to have low income. Abusive husbands were more likely to be less educated, have no stable job, use tobacco, alcohol or narcotics and have more behavioural problems than husbands of participants who did not report abuse.

Our results show that there is a relationship between the use of violence by men outside the home and abuse of pregnant women. It has previously been reported that taking violent action against pregnant women is 3 times greater among men who use violence in society than among others [30].

Table 4 Selected characteristics of neonates in relation to abuse of the mother during pregnancy

\begin{tabular}{lccc}
\hline Outcome & $\begin{array}{c}\text { Abuse } \\
(\boldsymbol{n}=\mathbf{1 5 3})\end{array}$ & $\begin{array}{c}\text { No abuse } \\
(\boldsymbol{n}=\mathbf{1 6 0})\end{array}$ & $\boldsymbol{P}$-value \\
\hline Pre-term birth, no. (\%) & $8(5.2)$ & $5(3.1)$ & NS \\
$\begin{array}{l}\text { Mean (SD) birth weight (g) } \\
\begin{array}{l}\text { Mean (SD) gestational age } \\
\text { (weeks) }\end{array}\end{array}$ & $3112(384)$ & $3204(340)$ & 0.02 \\
\hline NS & & & \\
\hline
\end{tabular}

المجلة الصحية لشرق المتو سط، منظمة الصحة العالمية، المجلد الخامس عشر، العدد ؟، 9 + ب 


\section{Conclusion}

Violence against pregnant women (physical, psychology and sexual assault) in our region of Islamic Republic of Iran (Khoram Abad) is common. The study shows that exposure to violence during pregnancy results in higher risk of poor outcome.

Knowledge of the prevalence of violence against pregnant women and who is at risk could assist in the planning of services for abuse prevention and for treatment of the health consequences of abuse. Therefore, more information is required concerning the prevalence of violence in pregnancy, including Afghan immigrants and pregnant refugees, and women with disabilities. Further research is also needed to identify the role of the health care system in prevention, management and rehabilitation as they relate to violence against pregnant women. Additionally, research is warranted on whether the identification of violence during pregnancy and treatment would result in lower use of prenatal care and improved pregnancy outcome.

\section{Acknowledgements}

We wish to express our sincere gratitude to Dr Hydar Ali Abedi and the staff of the Khoram Abad hospitals for their help and organization to accomplish this work. Financial support was received from Isfahan University of Medical and Health Sciences.

\section{References}

1. Jasinski JL. Pregnancy and domestic violence: a review of the literature. Trauma violence and abuse, 2004, 5:47-64.

2. Bullock $L$ et al. Abuse disclosure in privately and medicaid-funded pregnant women. Journal of midwifery \& women's health, 2006, 51(5):361-9.

3. Henning K, Klesges LM. Prevalence and characteristics of psychological abuse reported by court-involved battered women. Journal of interpersonal violence, 2003, 18(8):857-71.

4. Mirzaei $\mathrm{H}$. The prevalence of wife abuse in Isfahan Iran. Tehran family health journal, 1999, (19):23-33.

5. Mousavi SM, Eshaghian A. The prevalence of spouse abuse in Isfahan, Iran, 2002. Scientific Journal of Forensic Medicine (Islamic Republic of Iran), 2004, 33(10):41-8.

6. Stark E, Flitcraft A. Killing the beast within: women battering and suicidality. International journal of health services, 1995, 25(1):43-65.
7. Curry MA, Perrin N, Wall E. Effects of abuse on maternal complications and birth weight in adult and adolescent women. Obstetrics \& gynecology, 1998, 4:530-4.

8. Bohn DK, Tebben JG, Campbell JC. Influences of income, education, age, and ethnicity on physical abuse before and during pregnancy. Journal of obstetric gynecologic \& neonatal nursing, 2004, 33:561-71.

9. National Center for Injury Prevention and Control (NCIPC). Intimate partner violence: fact sheet. Atlanta, Georgia, Centers for Disease Control and Prevention (http://www.cdc.gov/ncipc/factsheets/ ipvfacts.htm, accessed 30 September 2005).

10. Yost NP et al. A prospective observational study of domestic violence during pregnancy. Obstetrics \& gynecology, 2005, 106(1):61-5.

11. Webster J, Chandler J, Battistutta D. Pregnancy outcomes and health care use: effects of abuse. American jour-

المجلة الصحية لشرق المتو سط، منظمة الصحة العالمية، المجلد الخامس عشر، العدد ب، 9 +. 
nal of obstetrics \& gynecology, 1996, 174(2):760-7.

12. Coker AL, Sanderson M, Dong B. Partner violence during pregnancy and risk of adverse pregnancy outcomes. Paediatric \& perinatal epidemiology, 2004, 18(4):260-9.

13. Goodwin MM et al. Pregnancy intendedness and physical abuse around the time of pregnancy. Maternal and child health journal, 2000, 4:85-92.

14. Murphy CC et al. Abuse: a risk factor for low birth weight? A systematic review and meta-analysis. Canadian Medical Association journal, 2001, 164(11):1567-72.

15. McFarlane J, Parker B, Soeken K. Abuse during pregnancy: frequency, severity, perpetrator, and risk factors of homicide. Public health nursing, 1995, 12:284-9.

16. Hudson WW, Mclntosh SR. The assessment of spouse abuse: two quantifiable dimensions. Journal of marriage \& family, 1981, 43:873-88.

17. Curry MA, Campbell RA, Christian M. Validity and reliability testing of the prenatal psychosocial profile. Research in nursing \& health, 1994, 17:127-35.

18. Brown JB et al. Development of the woman abuse screening tool for use in family practice. Family medicine, 1996 , 28(6):422-8.

19. Feldhaus KM et al. Accuracy of 3 brief screening questions for detecting partner violence in the emergency department. Journal of the American Medical Association, 1997, 277(17):1357-61.

20. Marshall L. Development of the severity of violence against women scales. Journal of family violence, 1992, 7:103-21.

21. Reid AJ et al. Using the ALPHA form in practice to assess antenatal psychosocial health. Canadian Medical Association journal, 1998, 159(6):677-84.
22. Johnson PJ, Hellerstedt WL, Pirie PL. Abuse history and nonoptimal prenatal weight gain. Public health reports, 2002, 117:148-56.

23. McCauley $\mathrm{J}$ et al. The battering syndrome: prevalence and clinical characteristics of domestic violence in primary care internal medicine practices. Annals of internal medicine, 1995, 123(10):737-46.

24. Newberger EH et al. Abuse of pregnant women and adverse birth outcome. Current knowledge and implications for practice. Journal of the American Medical Association, 1992, 267(17):2370-2.

25. McFarlane J, Parker B, Soeken K. Abuse during pregnancy: associations with maternal health and infant birth weight. Nursing research, 1996, 45(1):37-42.

26. Yost NP et al. A prospective observational study of domestic violence during pregnancy. Obstetrics \& gynecology, 2005, 106(1):61-5.

27. Courtois CA, Courtois Riley C. Pregnancy and childbirth as triggers for abuse memories: implications for care. Birth, 1992, $19(4): 222-8$.

28. Lent B, Morris P. The effect of domestic violence on pregnancy and labour. Discussion paper. Ontario, College of Family Physicians of Canada, 2000 (http:// www.cfpc.ca/English/cfpc/programs/patient\%20care/maternity/violence/default. asp?s=1, accessed 19 August 2008).

29. Curry MA. The interrelationships between abuse, substance use, and psychosocial stress during pregnancy: Women's health violence. Journal of obstetric gynecologic \& neonatal nursing, 1998, 27:692-9.

30. Parker B, McFarlane J, Soeken K. Abuse during pregnancy: effects on maternal complications and birth weight in adult and teenage women. Obstetrics and gynecology, 1994, 84(3):323-8. 